\title{
Nursing care and hospital dentistry in intensive care: palliative care for the elderly with covid-19 and associated comorbidities
}

\begin{abstract}
Objective: Describe nursing and dental care in the ICU and qualify palliative care for elderly patients with covid-19 and associated comorbidities.

Method: It is a descriptive-qualitative, documentary and even bibliometric statistical study, associated with the cohort method practiced by federal hospitalss.

Results: According to the statistical analyzes of the cohort and the theoretical-scientific basis, nursing and dentistry care in the ICU in palliative care for the elderly associated with comorbidities, is necessary and relevant in terms of their clinical and fundamental practice in accordance with the statistical studies raised.

Conclusion: The realization of this long-standing scientific study demonstrated the importance of nursing care and dentistry in the ICU, the importance of the pandemic related to Covid-19 and all the theoretical and philosophical basis for the implementation of palliative care.
\end{abstract}

Keywords: nursing, dentistry, intensive care, palliativecare, elderly, coronavirus infections
Volume 5 Issue 6 - 2020

\author{
Ms A MCS,' Neto LAN, ${ }^{2}$ Anna Nery Colasso \\ Albuquerqu, ${ }^{3}$ Welison Matheus Soares de \\ Medeiros, ${ }^{4}$ Arthur Saturnino Silva da Costa ${ }^{5}$ \\ 'Doctoral Student in Nursing, Federal universities, Brazil \\ ${ }^{2}$ Bachelorof Business Administration, Federal universities, Brazil \\ ${ }^{3} \mathrm{PhD}$ in Nursing, Federal universities, Brazil \\ ${ }^{4}$ Dental Surgeon, Federal universities, Brazil \\ ${ }^{5}$ Emergency Nurse,Federal universities, Brazil
}

\begin{abstract}
Correspondence: Welison Matheus Soares de Medeiros, Department of Dental Surgeon, Federal universities, Brazil, Tel +05583999999999, Email Teacherufpr@hotmail.com
\end{abstract} Received: November 25, 2020 | Published: December II,
2020

\section{Introduction}

Public health has faced a pandemic differentiated from the others already studied, caused by a virus considered "new" (SARS-CoV-2), which causes COVID-19. The first peopleto become ill were identified in Wuhan - China, in December 2019. It is known that COVID-19 is an acute respiratory disease, transmitted between people, with a high mortality rate in the elderly. The lethality rate in this population is of the orderof $14.8 \%$ and, in people with underlying medical conditions such as cardiovascular diseases, to $13.2 \%$, with diabetes mellitus $(9.2 \%)$, arterial hypertension $(8.4 \%)$, chronic respiratory diseases $(8.0 \%)$ and cancer $(7.6 \%){ }^{1}$

We are talking about a pathology of respiratory content, the period of immunological window varies from five to its full 14 days, and its transmission period is five days after the first symptoms appear. The most curious point of this disease is the severe acute respiratory syndrome (SARS), which affects between $19 \%$ and $30 \%$ of people who are going through this phase. In addition, $77 \%$ of them have a typical bilateral pneumonia, detected by computed to mography. According to all the media and aggravating factors of this pathology, the World Health Organization (WHO) started, onJanuary 1, 2020, several movements and actions to combat the identified out break. COVID-19 was already considered a public health emergency on January 30 and, on March 11, it started to be characterized as a pandemic, after infecting 118,000 people in 114 countries and leading to 4,291 deaths, which is only increasing. ${ }^{2}$

Since the period of immunological window mentioned above existsand the period of transmission is extremely different, the striking fact of this disease is the severe acute respiratory syndrome (SARS), which affects between $18 \%$ and $32 \%$ of patients. In addition, $75 \%$ of them have atypical bilateral pneumonia, detected by specific tests chosen by the medical professional. Observing this situation of seriousness of the disease, the World Health Organization (WHO) initiated, on January 1, 2020, several actions to combat the out break. COVID-19 was already considered a public health emergency on 30 January and, on 11 March, it became a pandemic, after infecting 118,000 people in 114 countries andcausing 4,291 deaths. ${ }^{3}$

Thereisalso a disorderofhealth systems in several countries that do not have adequate infra structure for the situation, prepared human resources, equipment and materials for the simultaneo uscare (atthesame time) of thousands of people infected with the pathology. In addition, the length of stay in the Intensive Care Unit (ICU) has been long, which increases the waiting time for critically ill patients. This situation requires care protocols and imposes on health professionals the difficultd ecision of choosing who can live or die.This situation aggravates the recommendation not to provide fans to people over 80 when demand exceeds supply. Currently, although hospitals are caring for and treating people infected with this disease with more advanced resources, there is a world wide care lessness with older elderly with suspicion or confirmation of COVID-19. ${ }^{4}$

Hospitalized patients with poor oral health are more likely to have unfavorable outcomes, due to the increased risk of respiratory infection. It is known that the risk of a poor evolution, due to respiratory infections in hospitalized patients, is increased in patients with poor oral hygiene. Recent systematic reviews point to the importance of protocols for chemical and mechanical control of oral colonization, to prevent unfavorable outcomes of systemic and oral health. ${ }^{5}$

Dental care in intensivecareunits (ICU) is important and costefficient for the prevention and control of diseases, such as respiratory infections. Oral care is perceived as highly important in patients on mechanical ventilation (MV) in the ICU by more than $90 \%$ of nursing 
professionals. In addition to the secares being considered difficult to perform, when they are not properly taught to the team, the task becomes more complex for those who perform it. ${ }^{6}$

It isimportant to determine the impact of oral care protocols on patients' health. When one of these protocols is present, the quality of the resolution of assistance activities is significantly higher, and the participation of the team involved in the assistance is more integral, showing the importance of the presence of these protocols. ${ }^{7}$

Much has been written about the humanization of care and, particularly, about the humanization of care for patients with death. At firstglance, it may seem quite punctual; however, the humanized care of a person, in his process of finitude, will be intrinsically linked to caring for that person, since his entry into primary care. Thus, the more (orless) humanized way of assisting the person, taking care of them in their terminality process, is inter connected to the way their care has been being since that moment. In this sense, wemay have, beforeus, a person out of therapeutic possibilities, more fragileor strength ened, according to what he has received in terms of humanization. ${ }^{8}$

Patients with advanced diseases, many of them terminally ill, are a reality in our hospitals, with serious difficulties for administrators, health professionals, family members, and for the patients themselves. There are several problems and challenges, highlighting, among others, the scarcity of human resources to deal with and respond to the demand soft he patient and his family; the lack of a national network that articulatesactions of prolonged and persistent medical interventions to the detriment of an approach that relieves the patient'ssuffering; the lack of a home support network; and the fact that care at the end of a life time is not a priority for health policy managers. ${ }^{9}$

Thus, in view of the above, the following guiding question was elaborated: How can we academically explore nursing and dentistry care in the ICU for elderly people with covid-19 in palliative care and associated comorbidities? Since online dissemination represents a revolution in the model of production, distribution and updating of news continuously, expanding the knowledge of content published on websites about health, as well as about its interrelations and determinants, is important for information and education of society. In addition, it can impact individual actions, the population in general, the medical community and public policy makers.

In this direction, the present study aims to describe nursing and dentistry care in the ICU and to qualify palliative care for elderly patients with covid-19 and the associated comorbidities.

\section{Method}

This is a descriptive-qualitative, documentary and even bibliometric statistical study, associated with the cohort method practicedby federal hospitals. Its focus will be nursing care and dentistry in the ICU and qualify palliative care for elderly patients with covid-19 and associated comorbidities. ${ }^{10}$

To elaborate this study, the six stages of the bibliometric review and the stages of the cohort study that will be cited were used, in orderto organize the information collected. ${ }^{11}$

1st stage: elaboration of the guiding question. Its definition is the most important phase, as it determines the identification of what must bead dressed to contemplate the proposed theme. ${ }^{12}$

2nd stage: searchor sample in the literature. The search was carried out in a wide and diversified way in there liable databases, taking into account that the determination of the inclusion and exclusion criteria for selection of the material should be carried out in accordance with the guiding question.

3rd stage: data collection. In this stage it was defined what would be extracted from the selected studies using a previously prepare dinstrument, with the purpose of organizing the key information in a concise manner for the construction of the study. ${ }^{12}$

4th stage: critical analysis of the included studies. In this phase, data analysis was carried out in detail to ensure the validity of the review. Always taking into account the guiding question as the basis for allanalysis. ${ }^{12}$

5th stage: discussion of the results. In this phase, the results obtained in the research were discussed and a critical analysis was carried out on what was evidenced. ${ }^{12}$

6th stage: presentation of the integrative review. This is the stage where the study was properly prepared. Containing enough information for the reader to analyze the study. ${ }^{12}$

The search for the studies was carried out in the Scopus Info Site (SCOPUS), Cumulative Index to Nursing\&Allied Health Literature (CINAHL), Medical Literature Analysis and Retrieval System Online (MEDLINE), Latin American and Caribbean Literature in Life Sciences databases Saúde (LILACS) and in the directory of journals Scientific Eletronic Library Online (SciELO), published between 2010 and 2020.

The research universe consisted of online articles in the health field, related to the proposed theme. The sample was determined considering the following inclusion criteria: beingavailable in the selected databases, contemplating the proposed theme, being available in full text, being article-type publications, in the period from 2010 to 2020.

The exclusion criteria were: dissertations and theses, as well as complete texts that are unavailable and do not include theproposedtheme. 36 articleswerefound, of which answered the guiding question. The data from the studies included in the research were categorized, analyzed and discussed, establishing direct relationships with the the oretical foundation in focus.

Thisis a documentary and observational cohort study, linked to a larger project, the sample of this study is composed of several patients whose hospitalizations occurred between March 2010 andOctober 2020 in federal public hospitals. ${ }^{13}$

This sample hasthepower (1-b) of $83.5 \%, 89 \%$ and $73.5 \%$ todetect, respectively, the medians of duration of exclusive, total and mixed breast feeding. The sample power was calculated a posteriori, based on the information produced in the data matrix of this study and took into consideration, respectively, $(\mathrm{x}=22,96 ; \mathrm{DP}=11,21) ;(\mathrm{x}=77,37$; $\mathrm{DP}=65,31) ;(\mathrm{x}=278,0 ; \mathrm{DP}=13,21) ;(\mathrm{x}=419,53 ; \mathrm{DP}=248,25)$; $(\mathrm{DP}=79,4) ;(\mathrm{DP}=220,55)$. The calculations took into account the significance level (a) of $5 \%$ for two-tailed tests. ${ }^{14}$

\section{Results and discussion}

According to the critical and selectivec on sent to quantify the theme, different to pics arose to be discussed: nursing and dental care for patients in the ICU, palliative care for the elderly with covid-19 and associated comorbidities. ${ }^{15}$

ith COVID-19 in the health system, the content of the publications showed the difficulties faced by each country in the face of the 
pandemic and the need for health systems support to health professionals, related to safety equipment and others for assistance to patients hospitalized by COVID-19, including mechanical ventilators in Intensive Care Unit (ICU) environments. ${ }^{15}$

The responsibility of the professionals working on the front line against the disease stands out: The high contagion rates and the serious effects caused on a relatively high percentage of the population raised to the limit of our sanitary system (Spain, 9); Hospitals are preparing for the unpreparable: the increase of patients in the ICU. Number of critically ill patients with COVID-19 admitted to the ICU grew 20 times in less than three weeks (Portugal, 6). In the category Work process of the health teamand its concern with contagion, the content soft he journalistic articles pointed out the daily concern of the press with the work process of the health professionals and with their own safety, due to the risk of contagion with the COVID-19 that increases as more patients are treated in the ICU. ${ }^{16}$

In this sense, it is possible to observe, in the different countries, matters that highlight safety as something essential for everyone: At the end of the shift, the ritual of removing the equipment is even more demanding, because for each piece removed it is necessary to disinfect the hands. Already properly equipped and disinfected, the team members, mostly nurses, enter the unit where hard work begins to save the sick. Lusa was able to assist the placement of a patient in the prone position to improve his oxygenation which required a real team work. ${ }^{17}$

The results obtained by the word clouds technique supported the construction of the thematic categories and show the reflection of the pandemic, its implications for the care of the elderly and the measures proposed in different countries for the control of the new corona virus. In allanalyzes, COVID-19 was identified as the main and recurring theme. ${ }^{18}$

However, in the selected content, there are words that refer to elderly patients, which denotes a concern of the press in disseminating news about the care to this portion of the population. Some differences between countries regarding the dissemination of news about hospital care for the elderly with COVID-19 are noticeable in Figure 1 and in the thematic categories identified, especially in European countries, which experienced the severity of the disease beforeAmerica, facing the filling of hospital seven before the first cases of deaths were registered in Brazil. This means that the articles published on this subject in Brazil in the period under investigation didnot yet fully address the issue investigated, as occurred in theother countries that are part of this study. ${ }^{19-22}$

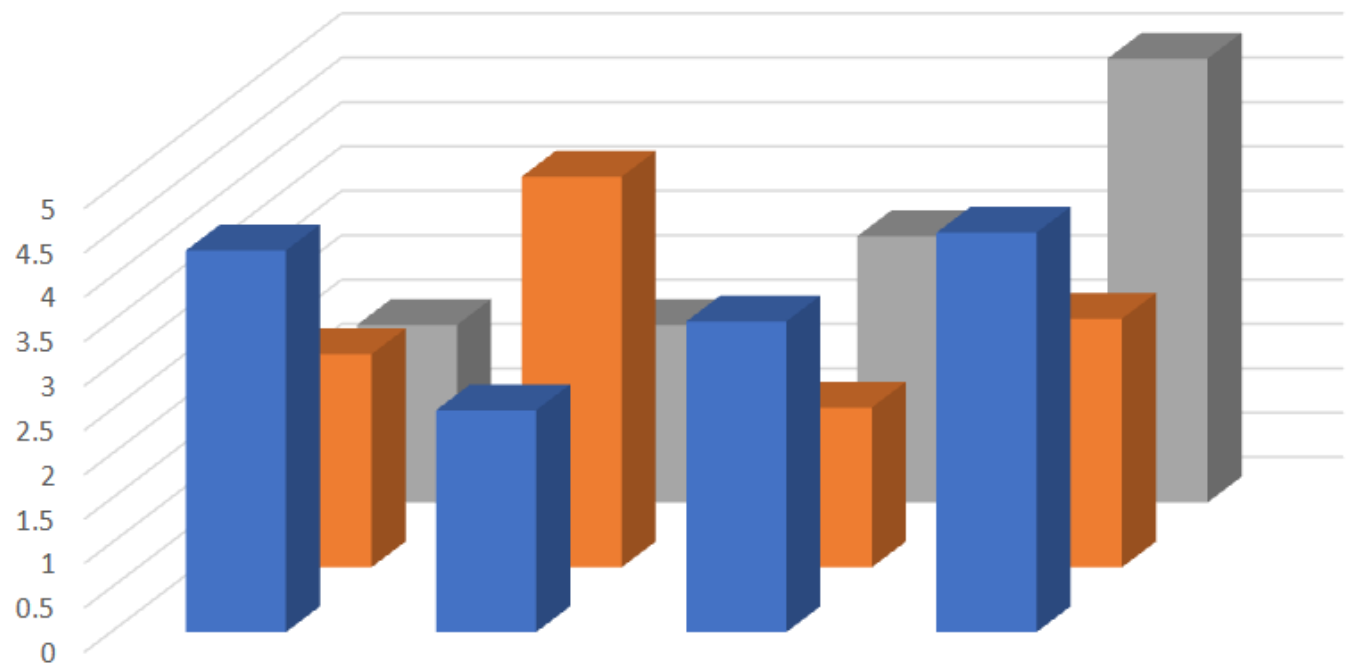

Figure I This graphic demonstrates the veracity of the text according to professional experiences and the description of the article for the current reasoning.

In category 1 , the importance of providing human and material resources for the care of individuals with acute respiratory failure stands out, sincethe major problem reported in the media survey edis the ability of health systems to deal with fluctuations in demand, especially with the increase in elderly patients, who need respiratory support. The difficulties in offering hospital careto more severe patients are highlighted due to the very restriction of the ICU hours, the limited physical capacity and the insufficient number of professional sprepared for this assistance. In addition, it should be mentioned that professionals working in the ICU environment generally experience physical exhaustion, receive low wages and deal with in adequate working conditions..$^{23-26}$

It is a fundamental characteristic of this experiment to point out that human (intensive) care takes a long time in this aspect, which increases the waiting time for critical patients for this resource. Such a situation requires assistance protocols and imposes on professionals a difficult decision to choose who canliveor die according to these humanistic and unequal needs..$^{27-30}$
The ethical issues presented in category three are due to the increase in the number of patients who need ICU beds in countries such as Spain, Italy and the United States, which has imposed some ethical dilemmas on health professionals, especially with regard to the choice who may or may not use a mechanical respirator. This situation can be seen in Figure 1, with its determined words, and identified in category 3 of the analyzed news papers. As the emerging epidemicis leading to a substantial increase in the number of patients requiring prolonged ventilatory support for acute respiratory failure, severe imbalances have occurred between the population's clinical needs and the general availability of ICU resources.

\section{Conclusion}

Hospital care for the elderly with COVID-19 was quickly disseminated in all countries and points out the need to reorganize health systems to serve the elderly population due to the irfragility and the lack of trained professionals to offer assistance to this clientele. The pandemic of the new coronavirus, COVID-19, reached all 
countries gradually and the journalistic articles analyzed disclosed the worrying reality of health care for the elderly population and the lack of training for health professionals in this situation.

The number of deaths gradually increased and brough thealth systems closer to collapse day after day, especially in Europe, where the proportion of elderly people is higher. This situation imposed on health professionals an ethical dilemma also widely publicized by these media: deciding between the life and death of the elderly. The theme proposal was the elderly, but only in the newspapers of two countries, United Statesand Portugal, there was mention of the nurse, although restricted.

The pandemic in the 21st century brings us important reflections for the planning of health systems, preparation and valorization of professionals to serve people of different age groups, especially the elderly. Thus, one of the challenges facing society, health managers and health professionals is the implementation of policies suitable for the elderly, which ensure their rights. At thesame time, and no less important, health professionals must be guaranteed the right and the duty to follow the ethical precepts of human rights, as per the oath of the profession, so as not to harm the principles of human dignity.

About half of Brazilian intensive care units offer some type of dental service at the bedside, despite varying in the details of this provision. Dental work in intensive care unitsis irregular at the national level, and the provision of servicesis performed in a non-standard way. Institutions offering the bedside dentistry service tended to be more organized in terms of training and oral health service delivery protocols.

With regard to palliative care, the patient expects from the professional who takes care of him a human engagement, the establishment of a bond, a personal availability to be-with and, in this sense, investing in the relations hip with the patient requires establishing strategies that humanize the assistance. However, they go beyond the ontic instance only when singling out the patient; other wise, they become more techniques and standards to be followed.

\section{Acknowledgments}

None.

\section{Conflicts of interest}

Author declare that there is no conflict of interst.

\section{References}

1. Spyrides MHC, Struchiner CJ, Barbosa MTS, et al. Amamentação e crescimento infantil: um estudo longitudinal em crianças do Rio de Janeiro, Brasil, 1999/2001. Cad Saúde Pública. 2005;21:756-666.

2. The baby friendly initiative. the effectiveness of baby friendly accreditation in increasing breast feeding rates. 2008.

3. WHO collaborative study team onthe role of breast feeding on the prevention of infant mortality. effect of breast feeding on infant and child mortality due to infectiousn diseases in less developed countries: a pooledanalysis. Lancet. 2000;355:451-455.

4. Lambert ML, Palomar M, Agodi A, et al. Prevention of ventilatorassociated pneumonia in intensive care units: an international online survey. Anti microb Resist Infect Control. 2013;2(1):9.

5. United nations medical directors. Novel Coronavirus (2019-nCoV) prevention recommendations for UN Personnel, Families and Visitors. [Internet]. 2020.
6. World health organization. Prevención y control de infecciones enlos centros de atención de larga estancia enel contexto de la COVID-19. [Internet]. 2020.

7. Wu Z, McGoogan JM. Characteristics of and important lessons from the corona virus disease 2019 (COVID-19) outbreak in China: summary of a reportof 72314 cases from the Chinese Center for Disease Control and Prevention. JAMA. 2020.

8. World health organization. Report of the WHO-China joint mission on Corona virus disease 2019 (COVID-19). [Internet]. 2020.

9. Tong A, Sainsbury P, Craig J. Consolidated criteria for reporting qualitativere search (COREQ): a 32-item checklist for interviews and focus groups. Int J Qual Health Care. 2007;19(6):349-357.

10. Medicins sans frontières. Spain must urgently improve the care of elderly in COVID-19 response. 2020.

11. Campos LP, Lins T. Portuguese pandemic: anaccount of covid-19 in portugal. Espaço Economia. 2020;IX(17).

12. Aurilene Josefa, Cesar CS, Maurício CS, et al. Incarcerated health: profile of the multidisciplinary team provider of health assistance in prisons. International Archives of Medicine. 2017;1755-7682.

13. DE SOUZA, Maurício Caxias et al. The influence of nursing in the development of popular education in health. International Archives of Medicine. 2017; 1755-7682.

14. EITE, Djavan Gomes et al. The family health support core (NASF) and health practices: are there many challenges to Be overcome?. International Archives of Medicine. 2017;1755-7682.

15. Souza MC, Lins DR, Saraiva CNR, et al. Risk factors related to falls in elderly: a reflective study. MOJ Gerontol Ger. 2018;93(4):131-132.

16. Souza MC, Pereira WDF, Santos SR, et al. Male doula, why not? International Archives of Medicine. 2017;(9):1755-7682.

17. Souza MC, Araújo HS, Silva TTSM, et al. Treatment of venousulcer in the elderly: implications for nursing. MOJ Gerontol Ger. 2018;3(4):287-291.

18. United nations department of economicand social affairs (UNDESA), population division. World population prospects: the 2012 revision. New York: United Nations. 2013;1-94.

19. Meinberg MC, Cheade MF, Miranda AL, et al. The use of $2 \%$ chlorhexidine gel and tooth brushing for oral hygiene of patients receiving mechanical ventilation: effects on ventilator-associated pneumonia. RevBras Ter Intensiva. 2012;24(4):369-374.

20. Kiyoshi-Teo H, Blegen M. Influence of institutional guidelines on oral hygiene practices in intensive care units. Am J Crit Care. 2015;24(4):309318.

21. Gmur C, Irani S, Attin T, et al. Survey on oral hygiene measures for intubatedpatients in Swiss intensive care units. Schweiz Monatsschr Zahnmed. 2013;123(5):394-409.

22. Blum DF, Munaretto J, Baeder FM, et al. Influence of dentistry professionals and oral health assistance protocols on intensive care unit nursing staff. A surveystudy. RevBras Ter Intensiva. 2017;29(3):391-393.

23. Lima MCSC, Bitencourt MLS, Diniz ERS, et al. Care for the elderly in the urgency sector: a qualitative study. MOJ Gerontol Ger. 2018;3(5):385-387.

24. Lima MCSC, Diniz MLSBERS, Valença CNGA. The benefits of salon dance for elderly: systematic review. MOJ Gerontol Ger. 2018;3(5):370-374.

25. Lima MCSC, Diniz MLSBERS, Valença CNGAV. Falls in the elderly: a reflective study. MOJ Gerontol Ger. 2018;3(5):366-368.

26. Gibson R. Principles of nutritional assessment. 2nd ed. Oxford: Oxford University Press; 2005. 
27. Venancio SI, Saldiva SRD, Médici MCA. Tendência secular da amamentação no Brasil. Rev Saúde Pública, São Paulo, 2013;47(6):12051208 .

28. Souza TS, Maciel OB, Méier MJ, et al. Estudos clínicos sobre úlcera por pressão. Rev Bras Enferm. Brasília. 2010;63 (3);470-476.

29. Machado AF. Dobras cutâneas: localização e procedimentos. Motricidade. 2008;4:41-45.

30. Laflamme L, Engstrom K, Moller J, et al. Peervictimization during early adolescence: an injury trigger, an injury mechanism and a frequent exposure in school. Int J Adolesc Med Health. 2003;15:267-279.

31. Scheffer AC, Schuurmans MJ, van Dijk N, et al. Fear of falling measurement strategy, prevalence, risk factors and consequences among older persons. Age Ageing. 2008;37:19-24.
32. Vinson DC, Mabe N, Leonard LL, et al. Alcohol and injury. a casecrossover study. Arch Fam Med. 1995;4:505-511.

33. Neutel CI, Perry S, Maxwell C. Medication use and risk of falls Pharmacoepidemiol Drug Saf. 2002;11:97-104.

34. Petridou E, Mittleman MA, Trohanis D, et al. Transient exposures and the risk of childhood injury: a case-crossover study in Greece. Epidemiology. 1998;9:622-625.

35. Hoffmann F, Glaeske G. New use of benzodiazepines and the risk of hip fracture: A case-crossover study. Z Gerontol Geriatr. 2006;39:143-148.

36. Boemer Magali Roseira. Sobre cuidados paliativos. Rev esc enferm. 2009;43(3):500-501. 